\title{
Breast Hemangiopericytoma
}

National Cancer Institute

\section{Source}

National Cancer Institute. Breast Hemangiopericytoma. NCI Thesaurus. Code C40396.

A hemangiopericytoma arising from the breast. 